\title{
Reseña
}

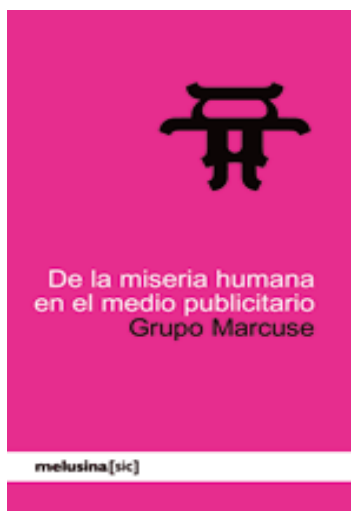

\section{De la miseria humana en el mundo publicitario Grupo Marcuse}

Traducción del francés de Javier Rodríguez Hidalgo

Año: 2006

206 páginas

ISBN: 84-934214-3-X

Precio: $12 €$

Para adquirir: http://www.melusina.com

Ma Elena Collado Sánchez, AIBR

En una primera lectura, sorprende la dureza con la que es tratado el tema de la publicidad y su repercusión en nuestra sociedad actual por parte de los autores del libro, pero una vez que se reflexiona sobre lo leído, podemos ir descubriendo los motivos que han alentado a dichos autores a realizar esta crítica feroz contra el sistema publicitario.

Para comprender y valorar mejor la importancia de este texto, conviene saber que los componentes del denominado Grupo Marcuse (Mouvement Autonome de Réflexión Critique à I'Usage des Survivants de L'Economie) son jóvenes profesionales liberales procedentes de distintos ámbitos del espectro cultural que decidieron conformar con sus variopintas aportaciones este "afilado" manuscrito contra la publicidad y sus entresijos.

Nos encontramos en sus páginas con un viaje pormenorizado por lo que los autores consideran el camino que hay que recorrer para que la ciudadanía, adopte el patrón de conducta suicida que supone un desmesurado consumismo.

Si en tiempos pretéritos se podía hablar -eufemísticamente- de un cierto control de los gobiernos sobre los medios de comunicación para inducir a la masa social hacia determinado tipo de actitudes, en la actualidad, los autores ponen de manifiesto el control de estos medios de comunicación por parte de grupos económicos privados con un poder sin parangón. Estos grupos que desde la sombra mueven los hilos de la marioneta social, son conscientes de que para que exista crecimiento y una economía fuerte es preciso un aumento de la producción que inexorablemente debe ir paralelo a un incremento en el consumo del producto de turno, para lo cual es imprescindible un aumento del estímulo de consumo, sin freno, sin medida. 
Para los autores la publicidad es el arma que utiliza el capitalismo feroz para conseguir sus objetivos, influenciando los comportamientos de los consumidores con unos mensajes que, más allá de la información, rallan en la propaganda más descarada.

¿Qué se esconde tras ese gasto salvaje de tiempo, trabajo, creatividad y dinero que conlleva el hecho publicitario? ¿Qué se nos oculta tras la fachada luminosa y colorista de los anuncios? ¿Cuáles son las consecuencias del poder práctico e ideológico que ejercen sobre nuestra vida las grandes empresas? Estas preguntas, algunas respuestas y posibles soluciones, son los ejes alrededor de los cuales se ha estructurado este libro. Un libro intenso y duro, extremo y pesimista en algunos capítulos, debido a la dificultad existente para la resolución del problema que aborda, pero que realiza con profundidad el análisis de una situación social en la que estamos inmersos y que cada día que pasa, se hace más evidente e insostenible. 